und beruft er sich dabei auch auf mich, ,wie dies Herr Mihók sehr gut weiß". Diese Berufung muß ich aber zurückweisen, denn obzwar es richtig ist, daß viele Neubeschreibungen ungarischer Duvalius-Arten nicht eben gelungen genannt werden können, so halte ich doch gerade die Beschreibung des Duv. Gyleki Breit für gut und zum Vergleich geeignet.

\title{
Beschreibung neuer Arten und Varietäten der Gattung Batocera (Col.).
}

\section{Von Bernhard Schwarzer (Aschaffenburg).}

Batocera Hauseri nov. spec.

§. B. lineolatae Cheor. simillima; major; capite majore; prothoracis maculis magnis plus minus confluentibus; mandibulis intus late obtuse dentatis; antennis articulis tribus basalibus nitidis valde rugatis, articulo $7-10$ apice parum uncinatis, 4-11 in modum Browni Bates asperatis; humeris valde productis in spinam antrorsum vergentem; ely trorum maculis antice in plagas magnas (2) confluentibus (macula elongata pone humeros), femora antica elongata rugata; tibiae intus valde denticulatae. Long. corp. $73 \mathrm{~mm}$. - Süd-China.

Collectio Hauser et mea.

Herrn Kgl. Universitätsprofessor Dr. G. Hauser in Dankbarkeit gewidmet.

Batocera Flachi nov. spec.

o. B. lineolatae Chevr. persimilis; antennis gracilioribus minus spinulosis, articulo 9 apice vix uncinato; elytris transversim truncatis, singula longius bispinosa. Long. corp. 40-50 mm. - ShanghaiNingpo. - Collectio Flach et mea.

Diese schöne, von lineolata durch abweichende Fühlerbildung und mit 4 Dornen versehenen Flügeldeckenspitzen gut charakterisierte Art, widme ich meinem lieben Freunde und entomologischen Lehrer, dem ausgezeichneten Entomologen Herrn Dr. Flach.

Batocera calanus var. bimaculata nov. var.

Maculis elytrorum omnino deficientibus, thorace maculis duobus parvis. Patria: Java.

Batocera calanus var. immaculata nov. var.

Maculae omnes deficientis. Patria: Java.

Batocera calanus Parry ist von allen anderen Batocera-Arten gut unterschieden durch die charakteristische Fühlerbildung. Das 3. Glied hat beim ô und + an der verdickten Spitze beid erseits (durchschuittlich 
je 2) kurze starke gerade Dornen (die der Innenseite gewöhnlich etwas kräftiger). Das ơ hatauch am 10. Fühlerglie deeinen kräftigen Hakendorn.

Vorstehende Varietäten fand ich bei den Revisionen verschiedener Cerambyciden-Sammlungen unter Batocera gigas Drapiez.

Batocera oceanica (Heller i. litt.). nov. spec.

Fusco-nigra; thorace immaculato; elytris pro maxima parte supra nitidis; pone basim griseo-fusco tomentosis; infra humeros haud dense nitido granulatis.

Long. of $55 \mathrm{~mm}$, o $60 \mathrm{~mm}$; lat. of $14 \mathrm{~mm}$, o $17 \mathrm{~mm}$. Patria: Insel Palau (Süd-Karolinen).

ô. Körper, Fühler und Beine braunschwarz, die Hinterränder der Abdominalsegmente glänzend gelbrot; Stirn runzelig punktiert, mit sehr feinem Mittelkiel; die Fühler überragen die Decken im 6. Gliede; das erste Glied gerunzelt; die Narbe nicht oder wenig deutlich begrenzt; das dritte Glied gerunzelt und auf der Unterseite fein gedornt; dieses und die folgenden Glieder an der Spitze mit sehr feinen Stacheln; vom vierten Gliede ab dicht mit dörnchenartigen Längskielchen besetzt.

Flügeldecken auf der Scheibe glänzend und fast unbehaart, im ersten Viertel mit glänzenden, schwarzen, unregelmäßigen Graneln mäßig dicht besetzt, diese hinter den wenig vorgęzogenen und kurz bedornten Schultern nicht dichter als in der Mitte, bis zur Spitze mit vorn größeren Punkten mäßig dicht besetzt, dazwischen sehr fein punktuliert. Jede Decke an der Spitze leicht ausgerandet, die spitz vorspringende Nahtecke nach außen divergierend und auf der Unterseite besonders stark behaart. Die den meisten Batocera-Arten eigenen Makeln der Flügeldecken im ersten Viertel in zwei rostbraunen Flecken vorhanden, die weiteren fein, oder kaum angedeuted.

Die charakteristische Behaarung dieser Art ist am Kopf und dem ungemakelten Halsschild, am Prosternum, den Seiten der Flügeldecken (mit Ausnahme in der Nähe der Schultern) und in der Mitte der Abdominalsegmente fein und bräunlich, in der Mitte der Mittelund Hinterbrust, an der Basis und im ersten Viertel der Decken dichter und rostrot, an den Seiten der Abdominalsegmente sowie der Mittelund Hinterbrust, hinter den Schultern und besonders auf dem Schild chen sehr dicht - teilweise filzig - und rostbraun.

Beine sehr fein reifartig grau behaart, Tarsen heller gefärbt. Das erste Glied der Vordertarsen beim ô an der Außenseite kurz bedornt.

+ etwas robuster gebaut, der Mittelkiel an der mehr gerunzelten Stirn viel feiner, die in den ersten Gliedern mehr glänzenden, weniger gerunzelten und spärlich mit Längskielchen besetzten Fühler überragen die Decken im 9. Gliede. 
Im Deutschen Entomologischen Museum zu Berlin-Dahlem und in meiner Sammlung.

Diese Art ist charakteristisch durch die wie abgerieben erscheinenden Flügeldecken, es liegen mir aber ganz frische, z. T. noch nicht ausgefärbte Stücke vor, welche die Originalbehaarung gut erkennen lassen.

\section{Zwei neue neotropische Calopterygiden (Odonata).}

Von Dr. F. Ris (Rheinau).

(Mit 2 Figuren im Text.)

Die folgenden zwei Einzelbeschreibungen mögen ihre Rechtfertigung finden in der etwas außergewöhnlichen Natur der Objekte und in der Unmöglichkeit, eine umfassendere Darstellung in absehbarer Zeit zu bringen.

1. Euthore Fassli nov. spec. (Fig. 1).

6 o Monte Socorro und Santa Margarita $2300 \mathrm{~m}$, West Cordillere Columbia, VII. 1909, leg. A. H. Fassl (Samml. Ris).

Am nächsten der $E$. fasciata Selys, doch verschieden durch eine Reihe von Merkmalen: größer als Exemplare von fasciata kolumbischer Herkunft; Grundfarbe der Flügel gelb; die postnodale schwarze Binde schmaler und mehr proximalwärts gelegen; die Opalbinde an deren proximalem Rand schmaler und gelb statt weiß, dichter, schräg begrenzt.

o. Occiput schwarz. Basisstück der Unterlippe gelblich, der Rest schwarz. Oberlippe schwarz mit zwei gelben Punkten. Ante- und Postclypeus schwarz. Genae oben und unten gelb, in der Mitte schwarz. Stirn und Scheitel schwarz, zwei rotgelbe Punkte zwischen den Fühlerbasen und zwei rotgelbe Keilfleckchen auf dem Occipitalrand. Thorax schwarz, hellgelb gezeichnet: schmale Linien nahe der Mediannaht, am ventralen Ende divergent und den Rand des tiefen Sinus begleitend; Querstrichel am Flügelsinus; etwas breitere Linie vorne an der Schulternaht nicht ganz bis zum dorsalen Ende; schmaler Keilfleck hinten am dorsalen Ende der Schulternaht; breitere Linie schräg über die vordere Seitennaht von der Coxa 2 nach dem dorsalen Rand des Metepisternum, am oberen Ende in einem Häkchen nach hinten gebogen; ebensolche Linie über die hintere Seitennaht, ventral gegabelt, ein Ast über das Stigma nach dem ventralen Ende der vorderèn Seitennaht; Saum der ventralen Kante des Metepimeron, gegabelt mit dorsalem Ast über die Mitte des Metepimeron. Ventralseite trüb gelbbraun, weißlich bereift, 


\section{$2 \mathrm{BHL}$ Biodiversity Heritage Library}

Schwarzer, B. 1914. "Beschreibung neuer Arten und Varietäten der Gattung Batocera (Col.)." Entomologische Mitteilungen 3, 280-282.

https://doi.org/10.5962/bhl.part.5090.

View This Item Online: https://www.biodiversitylibrary.org/item/38258

DOI: https://doi.org/10.5962/bhl.part.5090

Permalink: https://www.biodiversitylibrary.org/partpdf/5090

\section{Holding Institution}

Smithsonian Libraries

\section{Sponsored by}

Smithsonian

\section{Copyright \& Reuse}

Copyright Status: NOT_IN_COPYRIGHT

This document was created from content at the Biodiversity Heritage Library, the world's largest open access digital library for biodiversity literature and archives. Visit BHL at https://www.biodiversitylibrary.org. 